\title{
Short Rotation Forestry (SFR) in a Mediterranean Environment Under Limited Energy Inputs
}

\author{
Antonio Sergio De Franchi, Todaro Luigi, Teodoro Di Tommaso*, \\ Nicola Moretti, Stella Lovelli \\ Dipartimento di Scienze dei Sistemi Colturali, Forestali e dell'Ambiente, Università della Basilicata \\ Via dell'Ateneo Lucano 10, 85100 Potenza, Italy
}

Received: 15 December 2008. Accepted: 8 October 2010.

\begin{abstract}
The aim of this work is comparing the two year performance (diameter, total height and mortality) of twenty tree and shrub species in a semi arid environment. The research also wants to supply recommendation on the agronomic cropping techniques in areas where rainfall is the main limiting factor and water use is strictly limited.

Woody biomass is gaining increasing importance for energy production in Italy. During the last five years, roughly 5000 ha of Short Rotation Forestry (SRF) have been planted, mostly in northern Italy, especially using poplar clones. However, in Southern Italy, due to the poor rainfall and the lack of knowledge existing on the species to use, few groves have been established.

The studied groves were set in December 2005 in a Mediterranean area where the total year rainfall is not higher than $600 \mathrm{~mm}$ (mostly in autumn and winter).

Twenty species (Salix cinerea, Ulmus carpinifolia, Corylus avellana, Spartium junceum, Acer saccharinum, Morus alba, Saphora japonica, Eleagnus angustifolia, Fraxinus angustifolia (var oxicarpa), Sambucus nigra, Robinia pseudoacacia, Populus nigra, Albizia julibrissis, Populus alba, Salix alba, Ailanthus altissima, Alnus cordata, Ficus carica, Eucalyptus camaldulensis, Celtis australis) were planted in "collection" plots and set in singular plots on single rows (3 m X 0.5 m spacing).

Six species ( $R$. pseudoacacia, P. nigra, P. alba, S. nigra, E. camaldulensis, and A. altissima) were planted in eighteen random "experimental" split-plots, using single and twin rows ( $0.5 \mathrm{~m}$ spacing between plants). Plots had a rectangular plant spacing ( $3 \mathrm{~m}$ between singular and twin rows, $0.5 \mathrm{~m}$ on each row). Plant density was roughly 6670 cuttings $\mathrm{ha}^{-1}$ in "collection" plots with singular rows and 10950 cuttings ha $^{-1}$ in "experimental" plots using single and twin rows. The expected harvest interval ranges from 2 to 5 years, depending on the first results.

In the "collection" plots, the first results showed good performances in terms of diameter and total height of $R$. pseudoacacia, E. camaldulensis and E. angustifolia. The highest mortality percentage was recorded for $S$. nigra, $P$. nigra, P. alba both in "collection" and "experimental" plots. All other species showed mortality percentage lower than $20 \%$.
\end{abstract}

Key-words: short rotation forestry, biomass production, energy inputs.

\section{Introduction}

In the last years, the cultivation of fast growing species was boosted thanks to the increasing interest in biomass aimed to energy production.

These species are characterized by very short turns, 2-4 years, with high density spacing (from 5-10.000 to 15.000 plants/ha). The most used species are poplar (Populus nigra, Populus alba), eucalyptus (Eucalyptus camaldulensis), willow (Salix cinerea, Salix alba), and false acacia
(Robinia pseudoacacia), with the latter recording high yield of around 10-15 t/ha (Bisoffi et al., 2000; Paris et al., 2006).

In Basilicata, only experimental SRF specialized groves, set within the PROBIO and RAMSES projects, exist. Other similar studies were carried out in Tuscany, Piedmont and Latium (Maetzke and La Mantia, 2007).

At least in central and southern areas, especially if plants are grown in unfit locations and under the difficult Mediterranean climate, car-

* Corresponding Author: e-mail address: tditommaso@unibas.it 
rying out adequate trials in order to avoid dangerous expectations by farmers, is particularly important.

Hardcastle (2006) reports that even in the case of E. globulus, a species adaptable to the Mediterranean climates, grown in Spain and Portugal, poor productions were recorded. In experimental groves on semi-arid soils, Sochacki et al. (2007), point out that the production of some species (Eucalyptus and Pinus) at the third year is strictly correlated with spacing and plot exposure and slope.

In SRF, soil availability and quality play a crucial role because biomass production clearly clashes with the classical agricultural productions. Lately, especially in hilly and mountain environments, there is a great availability of soils which are semi-abandoned, arid, consumed by intensive cropping, salty, strongly sloping, hardly accessible, etc.. In these cases, the limiting factors can be chemical, physical, topographic or climatic and for these soils, no more used for agriculture or pasture, biomass production can be a good way to avoid their abandonment. However, only a few of these soils are able to support intensive SRF practices.

From a technical-agronomical point of view and especially in Mediterranean areas, no cropping model fitting the requirements of the energy productive rows, was defined. Important problems such as area choice, species and/or clone adaptability, production quantity and quality, constant production in the mid and long terms, profitability and environmental sustainability, are still far from being fully solved.

For instance, cropping system is extremely important for the success of the grove and the whole productive row functionality, as well as the quality of selected genetic material.

More specifically, we adapted the cropping system developed in northern Europe to grow willow for energy production to all species of our trial, comparing two high density grove systems: the first system was on single rows with around 6670 plants/ha, while the second was a very high density system, with 10950 plants/ha, foreseeing 1-5 year turns. Weed control was important during the first months after transplant and after each cutting to help taking root and offset emission, respectively. In the adopted systems, irrigation is taken into account only as an aid operation, because its economic cost limits its use.

The single row system allows a better weed control, both on the row and between rows, and a lower competition among the tree stumps. The use of twin or coupled rows facilitates the mechanized harvesting but makes weed control more difficult. In any case, determining the limits of the above cited cropping systems in the different environments is a very interesting topic and is strictly linked to the used species, the site characteristics and, last but not the least, the farm efficiency (availability of adequate means).

Thus, the aims of this work were:

i) comparing some biological parameters of 20 tree and shrub species, 6 of which planted under different spacing (double and single rows);

ii) evaluating the most productive tree species for biomass production in Mediterranean environments using limited energy inputs.

\section{Materials and methods}

\subsection{Study area}

The Baderta delle Murgine farm, managed by ALSIA, is located within the Aliano area, in the Matera district, in the mid Agri-Sauro catchment. It is placed $80 \mathrm{~km}$ from Matera and 110 from Potenza, at the $86^{\text {th }} \mathrm{km}$ of the trunk road n. 598 - Val d'Agri.

The overall farm area, 118 hectares, is located in the golenal area of Agri river and divided into two parts: one is downhill (in Pantano district, 40,80 ha), where the farm centre is located, while the other is uphill (Baderta district, 77,20 ha), two kilometres from the farm centre.

Field crops cover most of the farm land (60 hectares), while woods extend for around 15 hectares. Even some pear and nashi (Japanesea pear) tree varieties are grown, while other areas are covered by olive groves.

The area climate is characterized by a rainy but not very cold autumn-winter period and by a hot and dry spring-summer time. Rainfall amount changes from year to year ranging from 400 to $700 \mathrm{~mm}$. Very cold periods occur in the area with rainfall in winter and early spring.

The trail was carried out on a flat plot whose chemical and physical traits are shown in Table 1. The soil is alluvial, deep, silty-clayey and fertile. 
Table 1. Soil chemical-physical characteristics.

\begin{tabular}{llll}
\hline Parameters & Values & Texture $(\%)$ & Hydrology Constants \\
\hline Total N (\%) & 2.3 & Sand $(40.0)$ & Water field capacity (dry weight \%) $=31.50$ \\
Assimilable P (ppm) & 26.70 & Silt $(37.0)$ & Wilting point (dry weight \%) $=14.90$ \\
Exchangeable. K (ppm) & 227 & Clay (23.0) & Mean bulk density $\left(\mathrm{kg} / \mathrm{dm}^{3}\right)=1.20$ \\
O. M. (\%) & 3.64 & & \\
Active limestone (\%) & 6.20 & & \\
pH & 7.72 & & \\
Salinity (\%) & 1.15 & & \\
\hline
\end{tabular}

\subsection{Cropping operations}

In February 2006, a deep soil ploughing with a tyred tractor, $65 \mathrm{HP}$, with a double share plough was carried out, followed by crumbling (clod breaking, milling). Ploughing was necessary because of a hard horizon at $20 \mathrm{~cm}$ depth.

Before sapling transplanting, the plot was staked out to spot the exact points where the plants had to be placed, cutting too long or dry roots in order to help their taking root.

The plants, selected and certified, were transplanted on the $10^{\text {th }}$ of March 2006.

Together with the grove, a drip irrigation system was set to be used for the first year during possible hot periods. The system was linked with the farm water system.

Altogether, three inter-row weeding operations were carried out (15th of May, 15th of June and 25th of August).

\subsection{Studied species}

The choice of the species to be used in the trial was carried out according to the land characteristics and the species ecological requirements and potential production.

The chosen species were: Salix cinerea, Ulmus carpinifolia, Corylus avellanea, Spartium junceum, Acer saccharinum, Morus alba, Saphora japonica, Alaeagnus angustifolia, Fraxinus angustifolia, Sambucus nigra; Robinia pseudoacacia, Populus nigra, Albizia Julibrissin, Populus alba, Salix alba, Ailanthus altissima, Alnus cordata, Ficus carica, Eucalyptus camaldulensis, Celtis australis.

\subsection{Experimental field}

The six plots, arranged in a randomized block and covered by the following species, Sambucus nigra, Robinia pseudoacacia, Populus nigra, Populus alba, Ailanthus altissima, and Eucalyptus camaldulensis, were replicated three times,

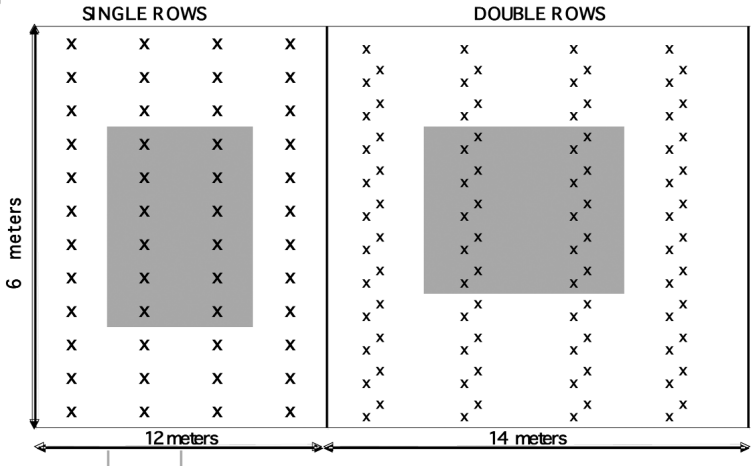

Figure 1. Experimental field plan. The grey area is the area where the sampling was carried out.

with 18 overall plots. The involved area was around $5000 \mathrm{~m}^{2}$. The plant number in the "twin row" plot is almost doubled compared with the "single row" plot.

In Figure 1 the scheme of a plot of the experimental field (replicated three times) is shown. The grey area is where the sampling of plant diameter and height was carried out, while plant taking root was assessed over the whole area. The distance between rows, both in single and twin rows, was equal to three meters. Along the row, there was a $50 \mathrm{~cm}$ distance between plants. Between the twin rows, the distance was equal to $50 \mathrm{~cm}$.

In the elementary plot with "single rows", 48 plants were transplanted while 92 plants were placed in the "twin row" plot. In the whole plot (single + twin rows), 140 plants were transplanted for each species.

\subsection{Catalogue field}

The experimental design of the grove called "catalogue field" was made up of 20 plots each containing the above mentioned single species.

The area of the single plot was $90 \mathrm{~m}^{2}, 3 \times 1$ meter spacing. In each plot, 30 plants were 


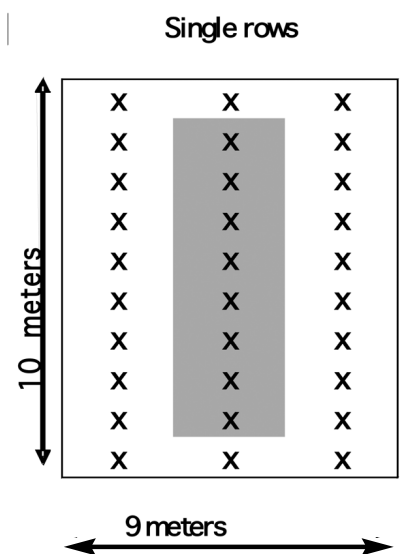

Figure 2. Catalogue field plan. The grey area is the area where the sampling was carried out.

transplanted. In Figure 2, the scheme of a single plot (replicated once only) is shown. The grey area is where diameter and height samplings were carried out, while the sampling for the taking root data was carried out on the whole area.

\section{Results and discussion}

\subsection{Experimental field}

In order to determine the potential productivity of the six transplanted species, the sampling of taking root percentage, plant collar diameter and total height, were carried out in each year.

Figure 3 shows the taking root data. The best results were achieved in $R$. pseudoacacia, E. camaldulensis and A. altissima. P. nigra showed better results than $P$. alba, while $S$. nigra showed unsatisfactory results ( $34 \%$ and $17 \%$, in the single and twin rows, respectively). In general, sin-

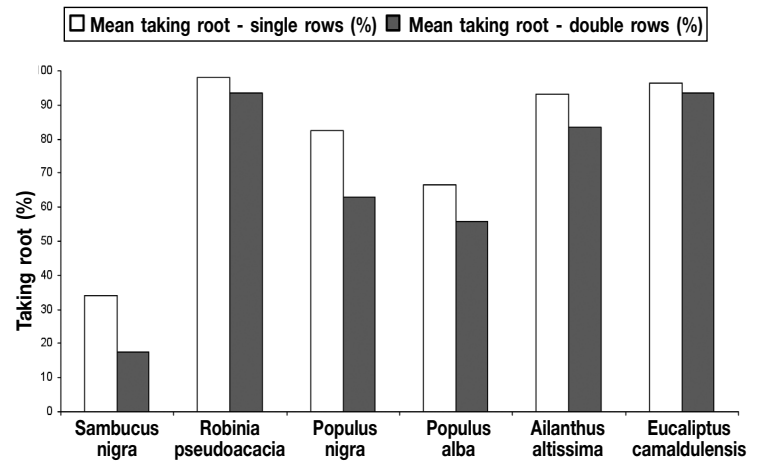

Figure 3. Rooting (\%) of the 6 species transplanted in the experimental field. gle rows showed better taking root results than twin rows. These data point out that hypogeous and epigeous competition phenomena occur since the first year. However, these results have to be clearly confirmed in the next years before coming to rash and uncertain conclusions.

Due to the huge number of faults recorded in S. nigra, we decided not taking into account this species in the next dendroauxometric analysis.

In January 2008, the sampling of collar diameter and total height of a plant group, was carried out.

\subsection{Plant diameter and height in the experimen- tal field}

The results shown in Figure 4, referring to plant diameter in single row experimental field, show good performances of $R$. pseudoacacia and $E$. camaldulensis. Unsatisfactory results were obtained in P. alba, while A. altissima and P. nigra showed intermediate results. In Tables 2 and 3 the statistic significativity of the obtained means, both in single and twin rows, are shown.

In the single row experimental field (Fig. 5), Robinia and Eucalyptus plants were the highest. P. alba and Ailanthus were the lowest, while P. nigra showed intermediate results. In Table 3, the statistical significativity of the obtained means are shown.

The mean diameter in the twin row experimental field (Fig. 6 and Tab. 2) points out that Robinia and Eucalyptus showed the greatest results in terms of diameter increment while P. nigra, Ailanthus, and P. alba did not show significant differences in terms of diameter values.

As regards to the height values (Fig. 7 and Tab. 3), data show that significant differences exist among all the studied species. Robinia

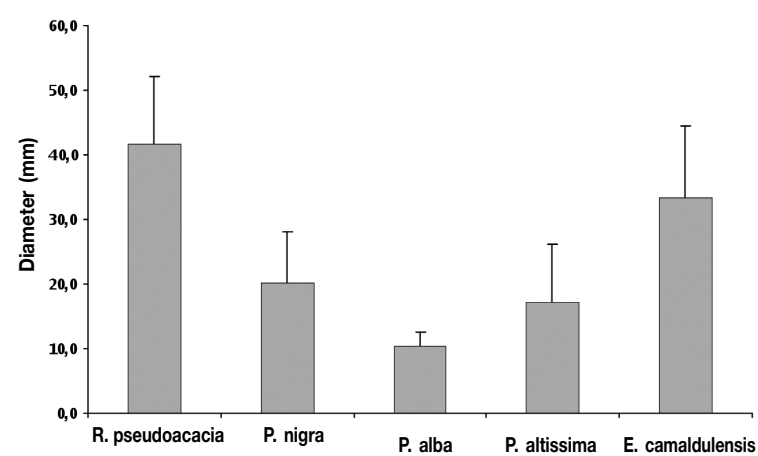

Figure 4. Average diameter of the 5 species planted in the experimental field: single rows. 
Table 2. Mean diameter with Standard Deviation and significativity of the 5 studied species transplanted in the experimental field: single and twin rows.

\begin{tabular}{|c|c|c|c|c|c|c|}
\hline \multirow{2}{*}{$\begin{array}{l}\text { Studied species } \\
R . \text { pseudoacacia }\end{array}$} & \multicolumn{2}{|c|}{$\begin{array}{c}\text { Single row } \\
\text { diameter }(\mathrm{mm})\end{array}$} & \multirow{2}{*}{$\begin{array}{c}\text { St. Dev. } \\
10.3\end{array}$} & \multicolumn{2}{|c|}{$\begin{array}{c}\text { Twin row } \\
\text { diameter }(\mathrm{mm})\end{array}$} & \multirow{2}{*}{$\begin{array}{c}\text { St. Dev. } \\
11.2\end{array}$} \\
\hline & 41.7 & $a$ & & 37.9 & $a$ & \\
\hline P. nigra & 20.2 & $c$ & 7.9 & 17.6 & $c$ & 5.6 \\
\hline P. alba & 10.5 & $d$ & 2.2 & 14.2 & $c$ & 4.7 \\
\hline A. altissima & 17.3 & $c$ & 8.9 & 16.4 & $c$ & 5.7 \\
\hline E. camaldulensis & 33.3 & $b$ & 11.2 & 30.4 & $b$ & 9.2 \\
\hline
\end{tabular}

Different letters are statistically significant for $\mathrm{p}<0.05$.

Table 3. Mean height with Standard Deviation and significativity of the 5 studied species transplanted in the experimental field: twin and single rows.

\begin{tabular}{|c|c|c|c|c|c|c|}
\hline \multirow{2}{*}{$\begin{array}{l}\text { Studied species } \\
R . \text { pseudoacacia }\end{array}$} & \multicolumn{2}{|c|}{$\begin{array}{r}\text { Single row } \\
\text { height }(\mathrm{mm})\end{array}$} & \multirow{2}{*}{$\begin{array}{c}\text { St. Dev. } \\
73.8\end{array}$} & \multicolumn{2}{|c|}{$\begin{array}{c}\text { Twin row } \\
\text { height }(\mathrm{mm})\end{array}$} & \multirow{2}{*}{$\begin{array}{c}\text { St. Dev. } \\
90.9\end{array}$} \\
\hline & 385.5 & $a$ & & 439.8 & $a$ & \\
\hline P. nigra & 201.2 & $c$ & 47.3 & 185.9 & $c$ & 46.5 \\
\hline P. alba & 121.6 & $d$ & 26.0 & 142.3 & $d$ & 33.1 \\
\hline A. altissima & 97.0 & $d$ & 39.6 & 87.7 & $e$ & 33.5 \\
\hline E. camaldulensis & 240.4 & $b$ & 70.7 & 238.6 & $b$ & 53.5 \\
\hline
\end{tabular}

Different letters are statistically significant for $\mathrm{p}<0.05$.

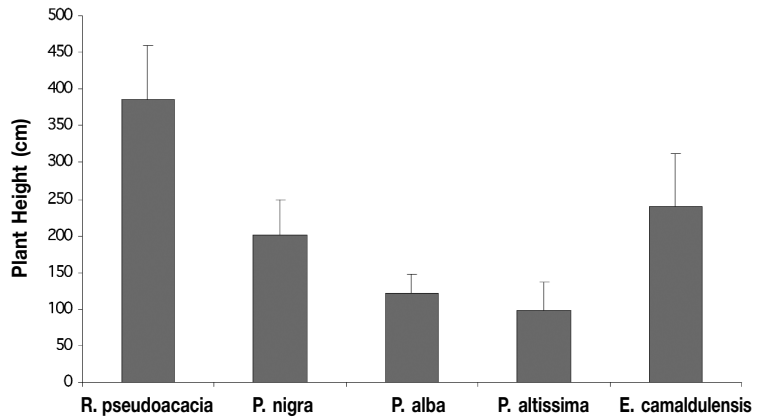

Figure 5. Average height of the 5 species planted in the experimental field: single rows.

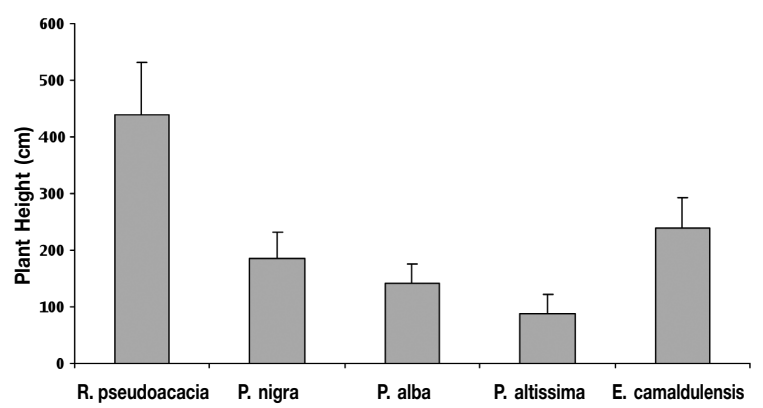

Figure 7. Average height of the 5 species planted in the experimental field: twin rows.

showed the greatest height values followed by Eucalyptus, P. nigra, Ailanthus and P. alba.

For a better understanding of the recorded

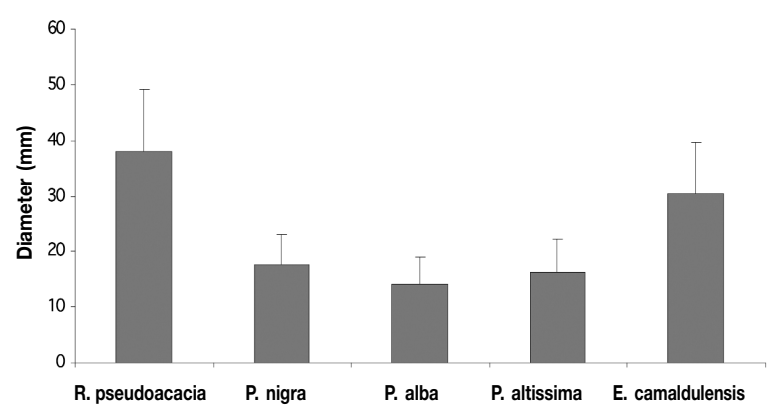

Figure 6. Average diameter of the 5 species planted in the experimental field: twin rows.

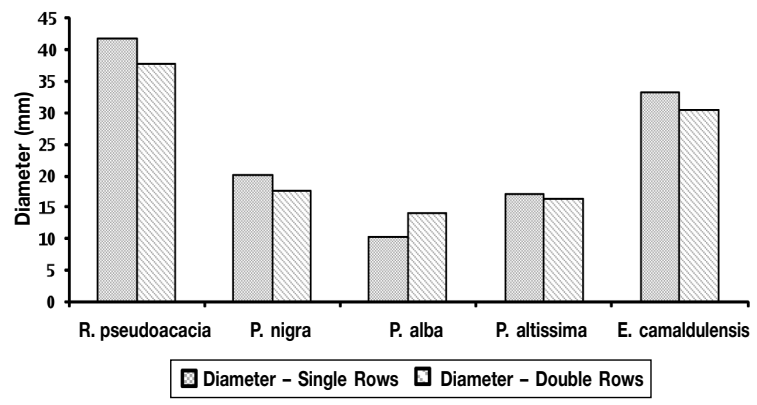

Figure 8. Comparison between mean diameters of the 5 species in single (plain histograms) and twin (striped histograms) rows, two years after transplant.

data, diameter and height values of plants grown in single and twin rows were compared. Figure 8 shows significant differences in terms 


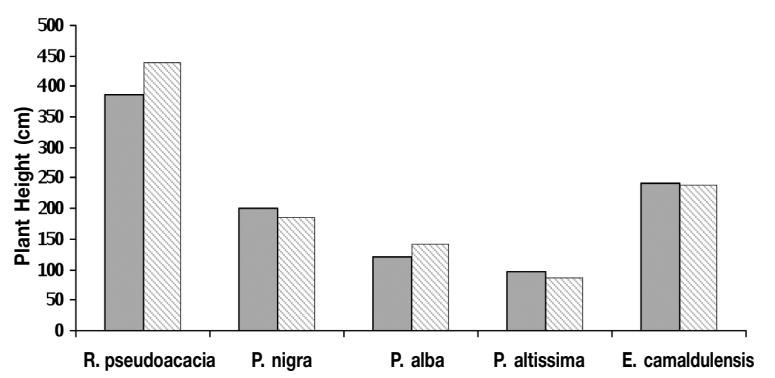

Figure 9. Comparison between the average height of the 5 species in single (plain histograms) and twin (striped histograms) rows, two year after transplant.

of diameter in P. alba only. Actually, for this species, the mean diameter in the twin rows was greater than in the single rows. For the other species, two years after transplant, the competition factor did not significantly affect the diameter growth of the grown plants.

The mean height of $R$. pseudoacacia and $P$. alba (Fig. 9) was significantly greater in the twin rows than in the single rows.

These data point out that, within the twin rows, hypogeous and epigeous competition phenomena occurred since the first year of the grove setting, at least in Robinia and P. alba.

\subsection{Catalogue field}

In terms of taking root, the worst results were achieved by Sambucus, P. nigra, Fraxinus angustifolia and P. alba. All the other species showed taking root percentage higher than $80 \%$.

The second year results of diameter growth (Tab. 4) point out the good performances of $E$. angustifolia, Robinia and Eucalyptus. The other species showed less interesting diameter growth. In particular, some species (Sambucus, Corylus, Ficus carica, Celtis, Saphora and Acer), did not achieved $10 \mathrm{~cm}$ diameter in two years.

As regards to the height values (Tab. 5), interesting results were achieved by Robinia and Eleagnus. The latter also grew bushy and very high, thus the only longitudinal sampling is not enough to show the real potentiality of this plant in terms of biomass production. At the final harvest, expected in the third year, we think that $E$. angustifolia could give a greater amount per hectare than the other species. The latter, but Eucalyptus, don't seem to fit energy biomass production. The difficult growth conditions, es-
Table 4. Mean diameter, with Standard Deviation and significativity level of the 20 species transplanted in the catalogue field.

\begin{tabular}{lclc}
\hline Species & \multicolumn{2}{c}{$\Delta(\mathrm{mm})$} & St. Dev. \\
\hline E. angustifolia & 55.2 & $a$ & 8.7 \\
R. pseudoacacia & 48.1 & $a$ & 11.1 \\
E. camaldulensis & 40.1 & $b$ & 16.6 \\
S. alba & 27.4 & $c$ & 9.4 \\
A. altissima & 24.8 & cd & 7.6 \\
S. junceum & 24.5 & cde & 3.1 \\
A. cordata & 20.0 & cdef & 3.9 \\
P. nigra & 18.7 & $\boldsymbol{d e f}$ & 8.3 \\
P. alba & 17.9 & $\boldsymbol{d e f g}$ & 5.4 \\
S. cinirea & 16.1 & $\boldsymbol{e f g h}$ & 4.8 \\
A. julibrissin & 13.9 & $\boldsymbol{f g h i}$ & 7.8 \\
F. angustifolia & 13.7 & $\boldsymbol{f g h i}$ & 1.5 \\
U. carpinifolia & 11.8 & $\boldsymbol{f g h i l}$ & 1.9 \\
M. alba & 11.6 & fghil & 2.9 \\
A. saccharinum & 9.5 & $\boldsymbol{g h i l}$ & 2.3 \\
S. japonica & 8.8 & hil & 1.8 \\
C. australis & 8.7 & $\boldsymbol{h i l}$ & 0.8 \\
F. carica & 8.5 & $\boldsymbol{h i l}$ & 1.3 \\
C. avellana & 6.8 & $\boldsymbol{i l}$ & 3.1 \\
S. nigra & 4.0 & $\boldsymbol{l}$ & 1.0 \\
\hline
\end{tabular}

Different letters are statistically significant for $\mathrm{p}<0.05$.

pecially for water availability and high temperatures in summer, seem to be a problem for a suitable economical production, in particular for those species not showing good performances in terms of diameter and height.

Table 5. Mean height with Standard Deviation and significativity level of the 20 species transplanted in the catalogue field.

\begin{tabular}{|c|c|c|c|}
\hline \multirow{2}{*}{$\frac{\text { Species }}{R . \text { pseudoacacia }}$} & \multicolumn{2}{|c|}{ Height $(\mathrm{cm})$} & \multirow{2}{*}{$\begin{array}{c}\text { St. Dev } \\
65.1\end{array}$} \\
\hline & 404.4 & $a$ & \\
\hline E. angustifolia & 353.8 & $b$ & 50.8 \\
\hline E. camaldulensis & 252.0 & $c$ & 81.4 \\
\hline P. nigra & 190.0 & $d$ & 28.3 \\
\hline S. alba & 181.4 & $d$ & 59.8 \\
\hline S. junceum & 175.3 & $d e$ & 13.5 \\
\hline P. alba & 152.0 & def & 19.0 \\
\hline S. cinirea & 144.0 & defg & 27.6 \\
\hline A. cordata & 128.6 & efgh & 19.0 \\
\hline A. altissima & 121.6 & fgh & 33.8 \\
\hline U. carpinifolia & 113.8 & fgh & 22.8 \\
\hline M. alba & 101.7 & ghi & 14.5 \\
\hline F. angustifolia & 98.2 & ghi & 28.7 \\
\hline A. julibrissin & 85.0 & hil & 26.0 \\
\hline C. australis & 84.1 & hil & 15.3 \\
\hline A. saccharinum & 83.7 & hil & 27.2 \\
\hline S. japonica & 60.3 & ilm & 18.9 \\
\hline F. carica & 57.2 & ilm & 11.5 \\
\hline C. avellana & 39.3 & $\operatorname{lm}$ & 15.6 \\
\hline S. nigra & 27.7 & $m$ & 11.2 \\
\hline
\end{tabular}

Different letters are statistically significant for $\mathrm{p}<0.05$. 


\subsection{Potential production assessment}

There are several provisional equations that many authors (Cotana et al., 2006; Shiver and Brister, 1992; Verwijst and Nordh, 1992; Gwaze and Stewart, 1990; Payandeh, 1981) proposed for the assessment of the dry biomass achievable at cutting time. Such equations take especially into account plant diameter and height. Among the proposed equations, that by Senelwa et al. (1997), determined for several different short rotation forestry groves of Eucalyptus in New Zealand, seems to be highly adaptable to the studied grove. In this study, this equation was used only for the species (Eucalyptus and Robinia) that, together with E. Angustifolia, showed the best results in terms of diameter, height and overall growth. However, the peculiar bushy form of E. angustifolia did not allow us to use the above cited equation that was arranged for plant in monopodial form.

Anyway, the proposed equation is the following:

$$
W=\left(\left(1.22 x D^{2} x H\right) /(10000)\right.
$$

Where:

$\mathrm{W}$ is the dry matter in $\mathrm{kg}$;

$\mathrm{D}$ is the diameter in $\mathrm{cm}$;

$\mathrm{H}$ is the height in $\mathrm{cm}$.

Using diameter and height values recorded both in the catalogue and in the experimental fields (single and twin rows), an assessment of the dry matter production per hectare was achieved. We took into account that, according to the spacing, in the catalogue field 3333 plants/ha were allowed. In the single row part of the experimental field, the spacing allowed 6667 plants/ha, while in the twin row part of the same field the expected plant number were 10950 plants/ha.

Table 6. Assessment of the potential production in the second year in Robinia and Eucalyptus in single and twin rows.

\begin{tabular}{llrc}
\hline Species & Grove type & Plants /ha & $\begin{array}{c}\text { Dry matter } \\
(\mathrm{Kg})\end{array}$ \\
\hline Robinia & Catalogue field & 3333 & 3.8 \\
Robinia & Single row & 6667 & 5.5 \\
Robinia & Twin row & 10950 & 8.5 \\
Eucalyptus & Campo catalogo & 3333 & 1.7 \\
Eucalyptus & Fila singola & 6667 & 2.1 \\
Eucalyptus & Fila doppia & 10950 & 2.9
\end{tabular}

The assessed production data are shown in Table 6.

After two years from transplant and with limited energy inputs in terms of tillage and cropping operations, the expected productions could have a revealing value.

Especially in twin rows, Robinia gave a production equal to 8,5 of dry matter per hectare showing, at the same time, that the required energy inputs are greater in twin row system than in single row one. The expected production from single rows is around 5,5 t of dry matter ha ${ }^{-1}$.

Some authors (Paris et al., 2006) reported that not genetically selected Robinia plants transplanted in other centre and southern Apennines areas produced $5 \mathrm{t} \mathrm{ha}^{-1}$ year $^{-1}$ dry matter. Likely, these production values could be doubled using selected clones of Poplar and False acacia but it is clear that, at the moment, the economic advantage for SRF producers seems to be closely connected with the aids expected in terms of public contributions (RDP, etc.).

However, at the felling time next winter, new data from this trial will be useful to allow a real assessment of the obtainable production.

\section{Conclusions}

In southern environments, where water is the main limiting factor, a close experimentation is necessary to verify the productive power of the species normally used in SRF, the duration of their shooting power, the suitable cropping operations for each of them, etc.

The results of the first two years of the trial are only preliminary and indicative.

Moreover, they have to be interpreted under the characteristics of the different experimental site and the ecological needs of the grown species.

Results point out that within the experimental field, Robinia and Eucalyptus seemed to have better development chances and potentiality. On the contrary, the other species did not show good performances, at least so far.

As regards to the catalogue field, together with the good performances shown by Robinia and Eucalyptus, good results were also achieved by $E$ angustifolia and, at a lower level, Salix. The other species were not able to grow "signifi- 
cantly", even achieving a good taking root percentage.

\section{References}

Bisoffi S., Facciotto G., 2000. I cedui a turno breve (SRF). Sherwood, 59:21-24.

Cotana F., Bidini G., Fantozzi F., Buratti C., Bartocci P. 2006. L'influenza degli agenti meteorologici e delle caratteristiche del suolo sulla produttività e sulla qualità del combustibile ricavato da una piantagione di Robinia nella regione Umbria. $61^{\circ}$ Congresso Nazionale ATI, 12-15 settembre 2006, Perugia.

Gwaze D.P., Stewart H.T.L. 1990. Biomass equations for eight exotic tree species in Zimbabwe. Commonw. For. Rev. 69, 4:337-344.

Hardcastle P.D. 2006. A Review of the Potential Impacts of Short Rotation Forestry. LTS International Ltd., Penicuik, UK.

Maetzke F., La Mantia T. 2007. Produzione e utilizzazione delle biomasse dei rimboschimenti in Sicilia. L'Italia Forestale e Montana, 62, 5/6:437-451.
Paris P., Sacchetti R., Scarascia Mugnozza G., Pisanelli A., Cannata F., Todaro L. 2006. La robinia a turno breve vince nelle zone marginali. Terra e Vita, 48:7983.

Paris P., Todaro L., Sacchetti R., Scarascia Mugnozza G., Pisanelli A., Cannata F. 2006. La robinia per le piantagioni da biomassa in zone marginali. Alberi e Territorio, 10/11:22-27.

Payandeh B. 1981. Choosing regression models for biomass prediction equations. For. Chron., 57:229-232.

Senelwa K., Sims R.E.H. 1997. Tree biomass equations for short eucalypts grown in New Zealand. Biomass and Energy, 13:133-140.

Shiver B.D., Brister G.H. 1992. Tree and stand volume functions for Eucalyptus saligna. For. Ecol. Mgm., 47:21 1-223.

Sochacki S.J., Harper R.J., Smettem K.R.J. 2007. Estimation of woody biomass production from a shortrotation bio-energy system in semi-arid Australia. Biomass and Bioenergy, 31, 9:608-616.

Verwijst T., Nordh N. 1992. Non-destructive estimation of biomass of Salix dasyclades. Bioresourc. Technol., 41:59-63. 